\title{
ANALISIS STRATEGI BISNIS BENGKEL BERNAH AUTOMOTIF CAR DI KOTA BUMI
}

\author{
Appin Purisky Redaputri ${ }^{1}$,Eryck Arinaldo ${ }^{2}$ \\ Faculty of Economic and Business, Universitas Bandar Lampung \\ Jl. Z.A Pagar Alam No. 26 labuhan Ratu, Kedaton, 35142, Bandar Lampung Indonesia \\ Email : \\ appin@ubl.ac.id \\ eryckarinnaldo@gmail.com
}

\begin{abstract}
ABSTRAK
Bernah Automotif Car memiliki masalah yaitu grafik fluktuasi pendaparan dari waktu ke waktu selama tahun 2018 sampai 2019. Persentase perkembangan Tahun 2018 sebesar 2\% sedangkan Tahun 2019 sebesar 1\%. Hal ini mungkin karena strategi bisnis yang diterapkan tidak tepat, misalnya perusahaan tidak terlalu menggunakan metode promosi. Maka dari itu, untuk meningkatkan penjualan produk perusahaan memerlukan strategi bisnis yang tepat. Tujuan dari penelitian ini adalah Untuk menganalisis strategi bisnis yang tepat pada Bernah Automotif Car dan memperbaiki pendapatan pada Bernah Automotif Car.

Sumber data adalah kuisioner dan wawancara serta dokumentasi pada Bernah Automatic Car. Metode pengumpulan data yaitu data primer yang dilakukan dengan cara observasi, studi dokumentasi dan kuesioner. Hasil penelitian ini menunjukan bahwa Bengkel Bernah Automotif Car memperbaiki kualitas produk yang ada dan sesuai dengan iklan yang dipromosikan hal ini guna mendapatkan kepercayaan konsumen sehingga akan meningkatkan nilai penjualan pada Bengkel Bernah Automotif Car serta promosi penjualan.
\end{abstract}

Kata Kunci : Strategi Bisnis, dan Penjualan.

\section{Latar Belakang Masalah}

Bernah Automotif Car merupakan salah satu bengkel yang berlokasi strategis di tengah keramaian Jl. Raya Bernah 92 RT. 02/06 Bernah, Kel. Cage, kota alam. Kota Bumi Selatan, sehingga posisi geografisnya sangat menguntungkan. Sejak tahun 2013 luas bengkelnya sekitar 4 ruko, sehingga sangat luas dan bisa menampung mobil. Guna menarik lebih banyak konsumen, Bernah Automotif Car telah melakukan berbagai upaya, antara lain buka 24 jam, 
bahkan bersedia menjemput kendaraan untuk diperbaiki, serta meningkatkan pasokan dan kelengkapan suku cadang mobil. Dimungkinkan untuk membeli suku cadang lengkap (seperti oli mesin) dan berbagai suku cadang serta berbagai kebutuhan yang biasanya dibutuhkan konsumen di bengkel ini. Namun upaya yang dilakukan oleh pemilik bengkel tidak menghasilkan peningkatan jumlah pelanggan yang signifikan.

Padahal, dalam dua tahun terakhir, jumlah konsumen jasa perawatan di Bernah Automotif Car mengalami penurunan. Penurunan konsumen tidak terlihat jelas, namun mengganggu pemiliknya, dan jika dibiarkan akan menjadi masalah yang serius. Tabel berikut menunjukkan penurunan pendapatan dari waktu ke waktu dalam dua tahun terakhir.

Tabel 1 Pendapatan Bernah Automotif Car pada tahun 2018 - 2020

\begin{tabular}{|c|c|c|c|c|c|c|}
\hline \multicolumn{3}{|c|}{ Tahun 2018} & \multicolumn{2}{|c|}{ Tahun 2019} & \multirow[b]{2}{*}{ Jumlah } & \multirow[b]{2}{*}{$\%$} \\
\hline Bulan & Jumlah & $\%$ & Jumlah & $\%$ & & \\
\hline Januari & Rp44.750.000 & $0 \%$ & Rp47.327.100 & $0 \%$ & Rp40.000.000 & $0 \%$ \\
\hline Februari & Rp48.400.000 & $8 \%$ & Rp44.114.000 & $-7 \%$ & Rp38.400.000 & $-4 \%$ \\
\hline Maret & Rp50.100.000 & $4 \%$ & Rp45.324.000 & $3 \%$ & Rp30.000.000 & $-22 \%$ \\
\hline April & Rp44.568.000 & $-11 \%$ & Rp47.983.000 & $6 \%$ & Rp29.500.000 & $-2 \%$ \\
\hline Mei & Rp47.252.500 & $6 \%$ & Rp43.518.875 & $-9 \%$ & Rp37.250.000 & $26 \%$ \\
\hline Juni & Rp48.439.750 & $3 \%$ & Rp40.158.000 & $-8 \%$ & Rp38.400.000 & $3 \%$ \\
\hline Juli & Rp47.709.500 & $-2 \%$ & Rp38.776.562 & $-3 \%$ & Rp37.600.000 & $-2 \%$ \\
\hline Agustus & Rp49.161.500 & $3 \%$ & Rp42.384.500 & $9 \%$ & Rp39.150.000 & $4 \%$ \\
\hline September & Rp49.241.500 & $0 \%$ & Rp41.239.250 & $-3 \%$ & Rp39.220.000 & $0 \%$ \\
\hline oktober & Rp48.481.625 & $-2 \%$ & Rp45.916.250 & $11 \%$ & Rp38.450.000 & $-2 \%$ \\
\hline November & Rp48.297.300 & $0 \%$ & $\mathrm{Rp} 48.350 .000$ & $5 \%$ & & \\
\hline Desember & Rp52.835.750 & $9 \%$ & Rp49.031.000 & $1 \%$ & & \\
\hline Rata-rata & Rp48.269.785 & $2 \%$ & Rp44.510.211 & $1 \%$ & Rp36.797.000 & $0,3 \%$ \\
\hline
\end{tabular}

Sumber : Bernah Automotif Car, 2020.

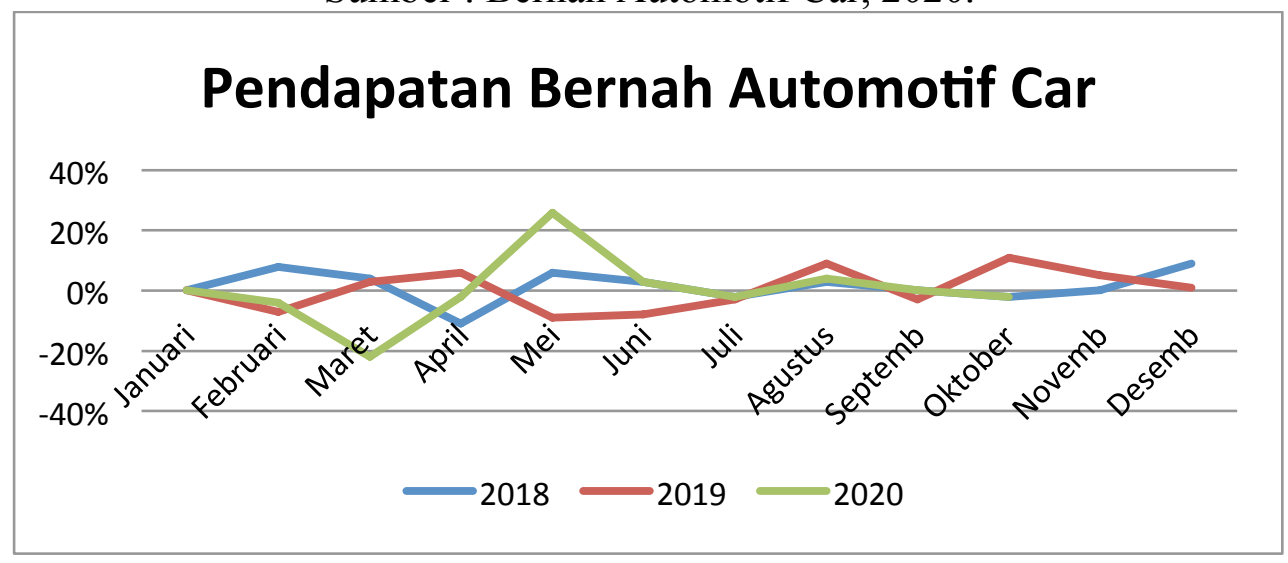

Gambar 1 Grafik Pendapatan pada tahun 2018 - 2020 
Sumber : Bernah Automotif Car, 2020.

Berikut grafik fluktuasi pendaparan dari waktu ke waktu selama tahun 2018 sampai 2019. Persentase perkembangan Tahun 2018 sebesar 2\% sedangkan Tahun 2019 sebesar 1\%. Sedangkan untuk masa pandemi Covid-19 Bernah Automotif Car mengalami penurunan pendapatan yang signifikan, dikarenakan pembatasan-pembatasan yang dilakukan oleh pemerintah. Sehingga kebanyakan konsumen berdiam diri dirumah untuk menjaga keamanan diri dari virus Covid-19. Persentase perkembangan Tahun 2020 sebesar 0,3\% sedangkan Tahun 2019 sebesar 1\%. Hal ini mungkin karena strategi bisnis yang diterapkan tidak tepat, misalnya perusahaan tidak terlalu menggunakan metode promosi. Karena itu, buat menaikkan pemasaran produk perusahaan memerlukan strategy bisnis yang tepat.

\section{Tujuan Penelitian}

Bersumber pada penjelasan persoalan diatas bahwa maksud dari riset ini yaitu

1. Buat mengkaji strategi bisnis yang tepat pada Bernah Automotif Car.

2. Untuk memperbaiki pendapatan pada Bernah Automotif Car.

\section{Pengertian Strategi Bisnis}

Rangkuti (2013) percaya bahwa strategy yaitu master plan yang komprehensif, yang menggambarkan macam mana perseroan bakal memperoleh segala target yang ditetapkan bersumber pada tugas yang sudah ditetapkan lebih dahulu. (Redaputri \& Barusman, 2018)

\section{Analisis SWOT(Strenghts, Weakness,opportunity,Threats)}

Analisis SWOT merepresentasikan "kekuatan" (strength company), "kelemahan" (weakness company), "peluang" (business opportunities) dan "ancaman" (obstacle to achieving goals). Kajian SWOT bermaksud buat mengetahui bisnis yang sebenarnya pantas demi keadaan perseroan, sehingga lebih mudah disadari bahwa setiap perusahaan dapat menggunakan teknologi analisis SWOT. (NARYONO, 2018)

\section{Metode Analisis}

\section{Jenis Penelitian}

1. Penelitian Kepustakaan (library Research)

2. Penelitian lapangan (Field Research)

\section{Desain Penelitian}

Desain riset yang digunakan yaitu analisis deskriptif. riset deskriptif menurut Linarwati (2016) adalah cara riset yang bermaksud mendefinisikan fakta yang terjadi, bagus fakta alam 
atau fakta ciptaan orang. Bahan yang dihimpun berupa deskriptif. Data tidak dimaksudkan untuk mencari penjelasan, menguji hipotesis, membuat prediksi, atau mempelajari implikasi.(Lampung, 2021)

\section{operasionalisasi Variabel}

Dalam penelitian ini terdapat dua variabel, yaitu daya saing dan strategi bisnis, berikut adalah teori yang digunakan oleh peneliti:

Menurut Tjiptono (2006), kata strategi berasal dari bahasa Yunani yang berarti strategi yang artinya seni atau ilmu menjadi seorang jenderal.Strategi juga dapat diartikan sebagai pembagian dan penggunaan kekuatan militer di wilayah tertentu untuk mencapai rencana tujuan tertentu. dari.(Redaputri \& Barusman, 2018)

\section{Jenis dan Sumber Data}

Jenis data yang digunakan dalam penelitian ini ada dua macam yaitu:

a. Data Primer

Menurut Umi Narimawati (2008: 98), data primer adalah "data dari sumber asli atau sumber pertama. Data ini tidak dapat disediakan dalam bentuk kompilasi atau bentuk file. Data. (Pratiwi, 2017) Sumber primer dalam penelitian ini adalah pengguna Bernah Automotif Car. Adapun data primer dalam penelitian ini yaitu: data pendapatan, data perkembangan jumlah konsumen, data perkembangan pendapatan dan data-data lain yang berhubungan dengan Bernah Automotif Car.

b. Data Sekunder

Menurut Sugiyono (2008: 402), data pembantu merupakan "sumber data yang tidak secara langsung memberikan data kepada pengumpul data”.(Pratiwi, 2017)

\section{Metode Analisis}

Metode analisis yang digunakan peneliti dalam penelitian ini adalah metode analisis kualitatif, yaitu metode yang menggunakan penalaran dan analisis untuk menganalisis data dengan berpedoman pada metode teoritis. Kalaupun ada data dalam bentuk digital, sifat analisisnya hanya sebatas memberikan informasi, mengevaluasi dan mengevaluasi data digital, kemudian membuat penjelasan dan kesimpulan. Alat analisis yang digunakan dalam penelitian ini adalah: Analisis SWOT (kekuatan, kelemahan, peluang dan ancaman). 


\section{HASII PENELITIAN DAN ANALISIS DATA}

\section{Gambaran Umum Perusahaan}

Bengkel Bernah Automotif Car merupakan salah satu bengkel yang secara geografis terletak pusat keramaian di Jl. Raya Bernah No. 92 RT. 02 / 06 Bernah, Kel. Kota Alam, Kec. Kota Bumi Selatan, sehingga memiliki letak yang strategis. luas bengkel ini sekitar 4 Ruko sehingga cukup luas menampung mobil dan telah berdiri sejak tahun 2013.

Dalam strategi bisnis terdapat beberapa aspek yang mempengaruhi strategi Bengkel Bernah Automotif Car yaitu aspek pemasaran, aspek keuangan, aspek sumber daya manusia dan aspek operasional. Pada aspek pemasaran Bengkel Bernah Automotif Car memasarkan produk dan promosi Bengkel Bernah Automotif Car melalui media sosial baik facebook, maupun instagram. Bengkel Bernah Automotif Car melakukan promosi gratis jasa ganti oli pada saat weekend berlangsung. Selain promosi pada media sosial Bengkel Bernah Automotif Car juga dilengkapi merk agar mempermudah konsumen untuk mengetahui lokasi Bengkel Bernah Automotif Car.
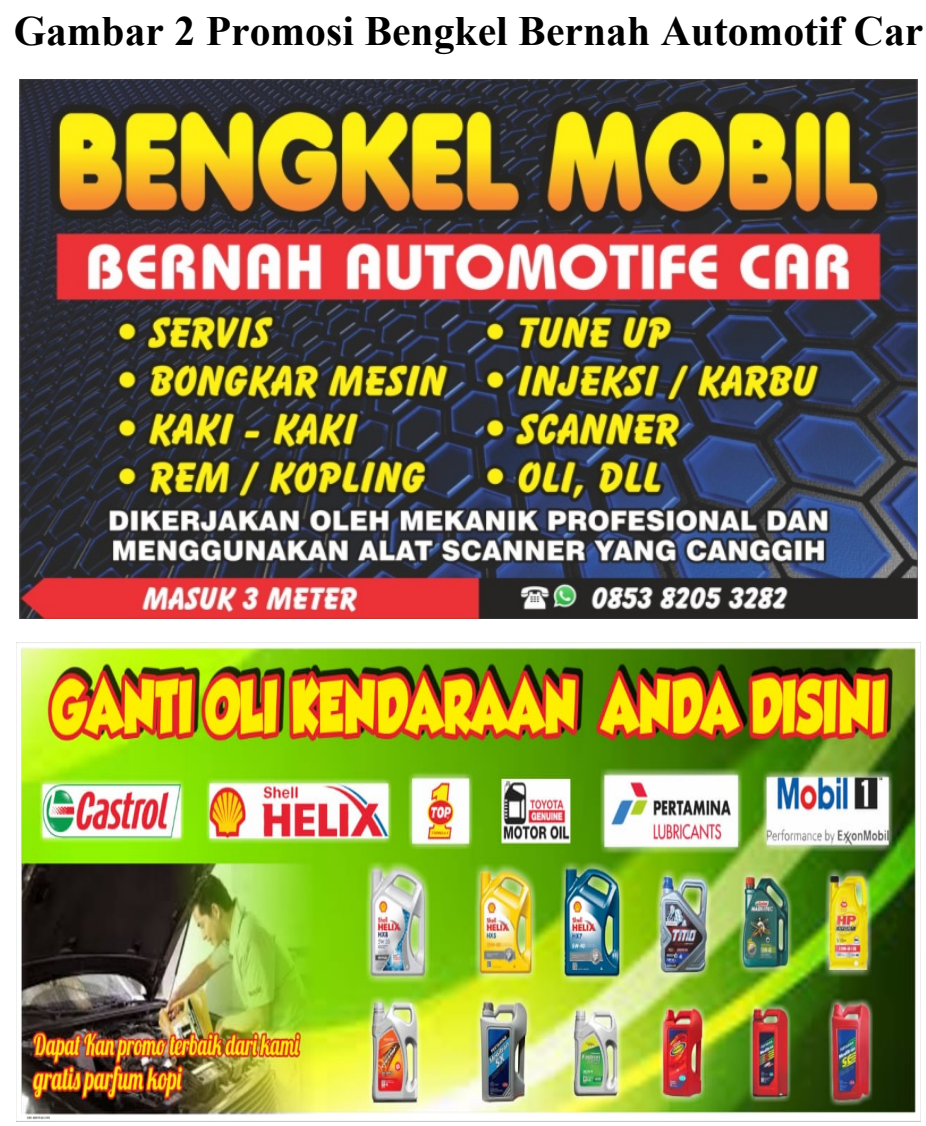

Sumber : Bengkel Bernah Automotif Car, 2020

Selain aspek pemasaran, aspek keuangan juga merupakan kesukesan usaha bisnis. Modal awal pembukaan Bengkel Bernah Automotif Car berasal dari modal pribadi pemilik Bengkel 
Bernah Automotif Car. Alat-alat sparepart mobil didapatkan dari sales ataupun produk dari Jakarta. Dari hasil wawancara penulis dengan pemilik Bengkel Bernah Automotif Car keuntungan pendapatan terbesar didapatkan melalui penjualan sparepart mobil, servis dan penjualan oli juga termasuk besar namun tidak sebesar penjualan sparepart mobil.

Selain aspek pemasaran dan keuangan, strategi bisnis juga melihat dari aspek sumber daya manusia agar aktivitas manajemen berjalan dengan baik, perusahaan harus memiliki karyawan yang berpengetahuan dan berketrampilan tinggi serta usaha untuk mengelola perusahaan seoptimal mungkin. Dalam hal ini Bengkel Bernah Automotif Car memiliki 8 karyawan. Karyawaan untuk cuci steam mobil ada 4 orang, untuk teknisi sporing/balancing 2 orang, montir ahli ada 3 orang, serta kasir 1 orang. Minimnya karyawan dikarenakan usaha Bengkel Bernah Automotif Car dikelola secara pribadi dan relatif usaha kecil.

Selanjutnya Aspek distribusi yang dilakukan pada Bengkel Bernah Automotif Car adalah dengan secara langsung mendistribusikan kepada konsumen, sesuai dengan jenis, jumlah, harga yang sesuai dengan konsumen. Bengkel Bernah Automotif Car memiliki jam operasional melayani konsumen Senin-Sabtu 07.30 - 17-00 dan hari Minggu 07.30-12.00.

IFAS (Internal Strategic Factors Analysis Summary) Bengkel Bernah Automotif

Car

\begin{tabular}{|c|c|c|c|c|}
\hline No & IFAS & Bobot & Rating & Bobot x Rating \\
\hline \multicolumn{5}{|c|}{ Kekuatan } \\
\hline 1 & Mekanik profesional dan handal & 0.20 & 4 & 0.80 \\
\hline 2 & $\begin{array}{l}\text { Harga service dan sparepart } \\
\text { mobil sangat terjangkau }\end{array}$ & 0.15 & 4 & 0.60 \\
\hline 3 & Selalu menjual Sparepart terbaru & $\mathbf{0 . 1 0}$ & 3 & $\mathbf{0 . 3 0}$ \\
\hline 4 & $\begin{array}{l}\text { Melakukan Iklan pada media } \\
\text { sosial facebook dan instagram }\end{array}$ & 0.15 & 3 & 0.45 \\
\hline & Sub Total & 0.60 & & 2.15 \\
\hline \multicolumn{5}{|c|}{ Kelemahan } \\
\hline 1 & Minimnya tenaga pemasaran & 0.10 & 3 & 0.30 \\
\hline 2 & Kurangnya montir dan teknisi & 0.10 & 2 & $\mathbf{0 . 2 0}$ \\
\hline 3 & Antrian yang panjang & 0.10 & 3 & 0.30 \\
\hline 4 & $\begin{array}{l}\text { Pelayanan yang dilakukan oleh } \\
\text { karyawan }\end{array}$ & 0.10 & 4 & 0.40 \\
\hline & Sub Total & $\mathbf{0 . 4 0}$ & & 1.20 \\
\hline & Total & 1.00 & & 3.35 \\
\hline
\end{tabular}

Sumber : Data diolah, 2020. 
EFAS (External Strategic Factors Analysis Summary) Bengkel Bernah Automotif Car

\begin{tabular}{|c|c|c|c|c|}
\hline No & EFAS & Pembobotan & Nilai & Bobot $x$ Rating \\
\hline \multicolumn{5}{|c|}{ Peluang } \\
\hline 1 & Banyak konsumen yang setia & 0.15 & 3 & 0.45 \\
\hline 2 & $\begin{array}{l}\text { Bengkel Bernah Automotif Car } \\
\text { termasuk bengkel yang lengkap }\end{array}$ & 0.15 & 3 & 0.45 \\
\hline 3 & Kualitas service sangat baik & 0.20 & 4 & 0.80 \\
\hline 4 & Ketahanan Sparepart baik. & 0.10 & 4 & 0.40 \\
\hline & Sub Total & 0.50 & & 2.10 \\
\hline \multicolumn{5}{|c|}{ Ancaman } \\
\hline 1 & $\begin{array}{l}\text { Bengkel Bernah Automotif Car } \\
\text { memiliki banyak pesaing }\end{array}$ & 0.05 & 2 & 0.10 \\
\hline 2 & Kesamaan Sparepart & 0.15 & 3 & 0.45 \\
\hline 3 & $\begin{array}{l}\text { Pesaing Bengkel Bernah Automotif Car } \\
\text { memiliki harga lebih murah }\end{array}$ & 0.10 & 2 & 0.20 \\
\hline 4 & $\begin{array}{l}\text { Pesaing gencar melakukan iklan } \\
\text { potongan harga }\end{array}$ & 0.10 & 3 & 0.30 \\
\hline & Sub Total & 0.50 & & 1.05 \\
\hline & Total & 1.00 & & 3.15 \\
\hline
\end{tabular}

Sumber : Data diolah, 2020.

Matrik IE Bengkel Bernah Automotif Car

\begin{tabular}{|c|c|c|c|c|}
\hline & & Total & r Faktor Strate & ternal \\
\hline & & KUAT & RATA-RATA & LEMAH \\
\hline & & $(3.0-4.0)$ & $(2.0-2.99)$ & $(1.0-1.99)$ \\
\hline \multirow{6}{*}{$\begin{array}{c}\text { Total Skor } \\
\text { Faktor } \\
\text { Strategi } \\
\text { Eksternal }\end{array}$} & TINGGI & Bernah & II & \multirow{2}{*}{$\begin{array}{c}\text { III } \\
\text { Penciutan }\end{array}$} \\
\hline & $(3.0-4.0)$ & Automotif Car & Pertumbuhan & \\
\hline & MENENGAH & \multirow{2}{*}{$\begin{array}{c}\text { IV } \\
\text { Stabilitas }\end{array}$} & V & \multirow{2}{*}{$\begin{array}{c}\text { VI } \\
\text { Penciutan }\end{array}$} \\
\hline & $(2.0-2.99)$ & & Pertumbuhan & \\
\hline & RENDAH & \multirow{2}{*}{$\begin{array}{c}\text { VII } \\
\text { Pertumbuhan }\end{array}$} & \multirow{2}{*}{$\begin{array}{c}\text { VIII } \\
\text { Pertumbuhan }\end{array}$} & \multirow{2}{*}{$\begin{array}{c}\text { IX } \\
\text { Likuidasi }\end{array}$} \\
\hline & $(1.0-1.99)$ & & & \\
\hline
\end{tabular}

Sumber : Data diolah, 2020. literatur : David (2012:344) 
Analisis SWOT Bengkel Bernah Automotif Car :

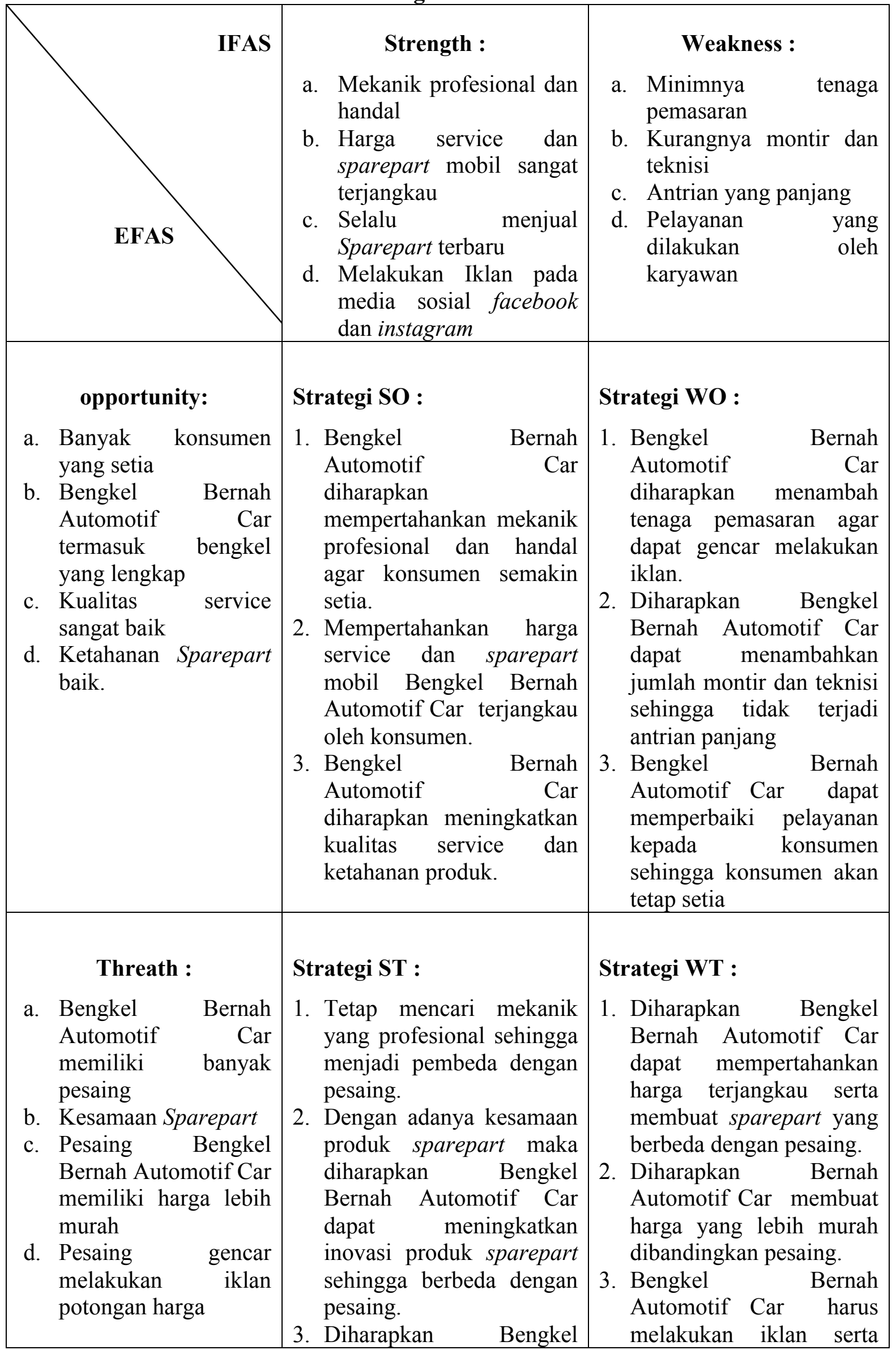




\begin{tabular}{|l|l|l|}
\hline & $\begin{array}{l}\text { Bernah Automotif Car } \\
\text { menerapkan promosi } \\
\text { harga diskon sehingga } \\
\text { dapat menarik perhatian } \\
\text { konsumen. }\end{array}$ & $\begin{array}{l}\text { memperbaiki pelayanan } \\
\text { karyawan sehingga } \\
\text { konsumen nyaman. }\end{array}$ \\
& & \\
\hline
\end{tabular}

Sumber : Data diolah, 2020.

Uraian pada tabel 4.10 di atas menunjukkan bahwa Bengkel Bernah Automotif Car perlu meningkatkan promosi dan menambah jumlah montir dan teknisi yang profesional. Untuk meningkatkan promosi yang dapat dilakukan adalah dengan memanfaatkan mediasosial ataupun memasang iklan pada marketplace, hal ini dimaksudkan untuk mengantisipasi gencarnya promosi yang dilakukan oleh pesaing. Menurut penulis bengkel lain dapat menjadi ancaman oleh Bengkel Bernah Automotif Car karena dengan hadirnya pesaing akan menjadi ancaman yang serius bagi perkembangan usaha di masa yang akan datang. Sparepart yang menjadi kesamaan, dapat menarik konsumen lain berpindah ke pesaing maka dari itu diharapkan Bengkel Bernah Automotif Car mencari perbedaan yang signifikan dalam memilih sparepart mobil.

\section{Kesimpulan}

Dari analisis SWOT dapat disimpulkan beberapa strategi yang dapat diterapkan oleh Bengkel Bernah Automotif Car dalam upaya untuk meningkatkan penjualan, adalah :

Bengkel Bernah Automotif Car memperbaiki kualitas produk yang ada dan sesuai dengan iklan yang dipromosikan hal ini guna mendapatkan kepercayaan konsumen sehingga akan meningkatkan nilai penjualan pada Bengkel Bernah Automotif Car serta promosi penjualan.

\section{Saran}

Dilihat dari uraian pernyataan dan hasil pembahasannya, Bengkel Bernah Automotif Car dapat mempertimbangkan beberapa saran:

1. Dalam melakukan strategi pemasaran perusahaan hendaknya perlu meningkatkan promosi dan mengembangkan produknya dengan inovasi yang baik, memanfaatkan mediasosial, hal ini dimaksudkan untuk mengantisipasi gencarnya promosi yang dilakukan oleh perusahaan pesaing. 
2. Hadirnya pesaing menurut penulis dapat menjadi perhatian lebih oleh perusahaan karena dengan hadirnya pesaing akan menjadi ancaman yang serius bagi perkembangan usaha di masa yang akan datang.

3. Kualitas produk masih belum memadai saat melakukan pengiriman, hal ini disebabkan oleh jauhnya lokasi dengan konsumen atau kurangnya perhatian karyawan yang betugas melakukan packing produk pada Bengkel Bernah Automotif Car jika dibandingkan dengan perusahaan pesaing.

\section{DAFTAR PUSTAKA}

Lampung, B. (2021). Lectura: Jurnal Pendidikan, Vol.12 No. 1, Februari 2021. 12(1), 1-14.

NARYONO, E. (2018). Analisis Swot Sebagai Dasar Strategi Meningkatkan Daya Saing Pada Anugrah Hotel. Jurnal Ekonomedia, 07(02), 17-31.

Pratiwi, N. I. (2017). Penggunaan Media Video Call dalam Teknologi Komunikasi. Jurnal Ilmiah Dinamika Sosial, 1(2), 202-224.

Redaputri, A. P., \& Barusman, M. Y. S. (2018). Strategi Pembangunan Perekonomian Provinsi Lampung. Jurnal Manajemen Indonesia, 18(2), 86. https://doi.org/10.25124/jmi.v18i2.1340 